\title{
Eye health knowledge and health-seeking behaviours in Ghana
}

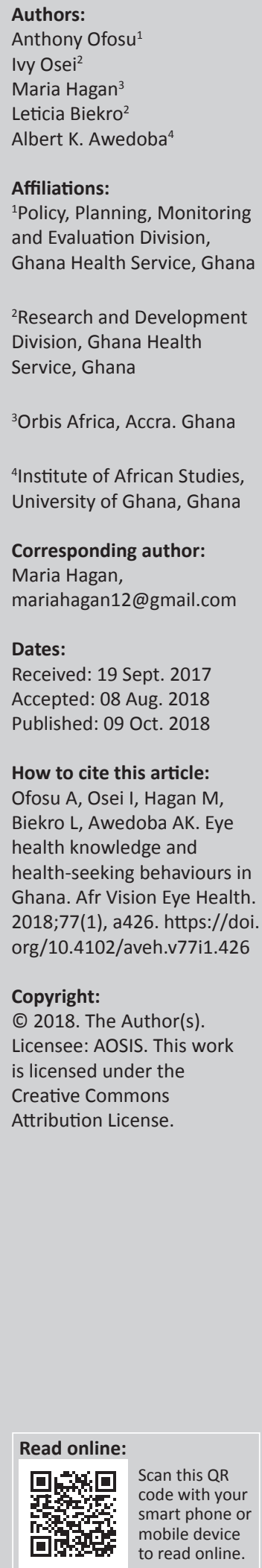

Background: To improve access to comprehensive eye health services within the community, an intervention study that sought to integrate primary eye care (PEC) into existing primary health care (PHC) services, namely Community-based Health Planning and Services (CHPS), was conducted.

Aim: To improve access to eye health at community level.

Setting: The study was conducted in Northern, Eastern and Western Regions of Ghana.

Methods: The study was a cross-sectional exploratory study, which employed both qualitative and quantitative methods. It used multistage cluster randomised sample design. The study involved a household survey, observation, focus group discussions (FGDs), in-depth interviews (IDIs) and informal discussions and case narratives.

Results: The findings of the baseline survey covered information on the eye health knowledge, and health-seeking behaviours at community level. Out of the total 1760 people interviewed, $52.5 \%$ were women. The educational level of the respondents was low, $35.7 \%$ had no education and only $3 \%$ had tertiary education. All the study communities, including $67 \%$ of survey respondents, said eye disease was the third most common health problem. Overall knowledge about specific diseases was low. Only 3\% and 5\% of respondents mentioned trachoma and glaucoma, respectively, as a cause of blindness. All community members tended to either seek help from the practitioner closest to them or else alternate between different practitioners.

Conclusion: The study showed that eye disease was a common health problem in all the communities. The community members desired eye care services manned by trained personnel close to them. Using CHPS appeared to be an option that can greatly improve access to eye care services in Ghana.

\section{Introduction}

Eye disease or ocular morbidity affects large numbers of any population. It includes vision impairing (VI) and non-vision impairing conditions (NVIC). Non-vision impairing conditions, which include refractive errors, conjunctivitis (allergic and infective), lid margin inflammation and watery eyes, can cause discomfort and transient vision disturbance and loss of productivity. Those affected would often need to seek medical advice. ${ }^{1}$ A study in Chakwal district in Pakistan on NVIC showed that $30.6 \%$ of 1670 people examined had NVIC, more than $50 \%$ of which were because of presbyopia. ${ }^{2}$ A Kenyan study on the prevalence and causes of ocular morbidity in the Mbeere district reported that $15.52 \%$ out of 3691 people examined had an ocular morbidity in at least one eye. The most common cause was presbyopia. ${ }^{3}$ Another ocular morbidity study in Kwara State in Nigeria found that $25.2 \%$ out of 3899 people examined had an ocular morbidity in at least one eye. ${ }^{4}$

In Africa, eye problems rank 6th to 8th among reasons for using health services, yet the eye care services offered are significantly below demand, with coverage of eye care needs estimated at $15 \%$ $-20 \%{ }^{5}$ A review of eye clinic data (2012) in Ghana showed that $50 \%$ of all eye diseases diagnosed, mainly conjunctivitis and refractive errors, could be managed at the primary level if trained eye health workers were available and appropriately equipped at this level. ${ }^{6}$ Many people at the community level often face various obstacles, like transportation, poor road network and financial constraints, and therefore do not have easy access to eye health professionals.

The serious shortage of human resources for eye health in Ghana, the maldistribution of skilled personnel, the deteriorating infrastructure and lack of equipment are major challenges of eye care services delivery. These challenges are complicated by the lack of awareness of the causes of eye 
diseases, many of which may be curable or preventable. Even those who are aware of the existence of eye care services will often not pursue treatment for sundry reasons, including real or perceived financial implications associated with going to the facility or even downright dread of the city or its ways.?

In the absence of eye care expertise, people visit traditional healers or chemists for help because they are close to the community and readily accessible. These healers and chemists invariably do not have appropriate training. They may tend to prescribe inappropriate treatment and make the problem worse or permanently damage the patient's sight. ${ }^{8}$

A rapid assessment of avoidable blindness (RAAB) study carried out in the Eastern Region of Ghana in 2009 indicated that the prevalence of blindness among people aged over 50 years was $4.2 \%$ and that $84.5 \%$ of all the causes were avoidable. Extrapolation of the data indicated that the prevalence of blindness for all age groups in the Eastern Region was $0.7 \% .{ }^{9}$ A recent Ghana national population-based survey on blindness and visual impairment has recorded $0.74 \%$ prevalence of blindness among all ages and $4.0 \%$ among people over 50 years. ${ }^{10}$

To reduce barriers to accessing health care, the Ministry of Health (MoH) and the Ghana Health Service (GHS) adopted the Community-based Health Planning and Services (CHPS) system as a national health policy. ${ }^{11}$ The CHPS is manned by Community Health Officers (CHOs). The service package for $\mathrm{CHOs}$ is focused mainly on maternal and reproductive health $(\mathrm{MRH})$, child health $(\mathrm{CH})$, treatment of minor illnesses, health education and the follow-up of defaulters and discharged patients ${ }^{12}$, but no primary eye care (PEC). Primary eye care has been defined as 'an integrated, participatory and inclusive approach to the eye health component of PHC consisting of promotive, preventive, curative and rehabilitative services' ${ }^{\prime 13}$ Integrating PEC into existing primary health care (PHC) services would facilitate access to a more equitable, effective and affordable eye care, particularly by the relatively poor in the rural communities. Since 2004, eye health in Ghana has been implementing activities to reduce the prevalence of avoidable blindness and increase coverage of eye health service delivery through the strengthening of national, regional and district capacities that ensure available, accessible, affordable and acceptable eye health to all people living in Ghana and the mobilisation of communities to participate actively in eye health. ${ }^{14}$ With inadequate eye health providers and lack of equipment and supplies, it has been difficult to provide service in hard-to-reach communities.

This article reports findings of the baseline study on eye health knowledge and health-seeking behaviours of community members in Ghana.

\section{Methods}

\section{Study design}

A cross-sectional exploratory study with pre- and postinterventional multistage cluster randomised sample design was used. The study employed both qualitative and quantitative methods.

The pre-intervention phase, the baseline, presented in this article involved review of documents, consultation with stakeholders using mainly qualitative research methods such as in-depth interviews (IDIs), observations, focus group discussions (FGDs), case narratives and informal discussions, among others. A crosssectional household survey using a structured questionnaire was also conducted. The respondents of the survey did not participate in the FGDs, IDIs or the case narratives.

In-depth interviews were one-on-one, conducted with a checklist of issues on eye health in the community. It involved open-ended questions, without constraining the respondent but probing further what the respondent said.

Focus group discussions involved the simultaneous interviewing of 8-10 people. It allowed respondents to listen to each other and agree or disagree with one another. Efforts were made to encourage every member of the group to express himself or herself. While FGD and IDI emphasised perceptions, case narratives, based on actual occurrences and history of events, validated the perceptions.

\section{Study site}

The country was demarcated into three ecological zones: northern savanna, comprising of Northern, Upper East and Upper West Regions; central tropical forest, consisted of Brong Ahafo, Ashanti, eastern and northern parts of the Volta regions; and southern zone (coastal savanna, mangrove and forest) made up of Greater Accra, western, central and southern parts of the Volta regions. Based on the number of functional CHPS zones, one region with the highest number of functional CHPS zones was selected per ecological zone. A functional CHPS zone is defined as a geographically welldefined area within a sub-district with an assigned $\mathrm{CHO}$ who has started offering services by home visits to patients in the zone. The Northern, Eastern and Western Regions were selected for the study. One district was selected from each of the three regions based on the availability or proximity of a referral facility. The study districts were east Gonja in the Northern Region, Tarkwa Nsuaem in the Western Region and Kwahu north in the Eastern region. Two CHPS zones per district were selected.

\section{Recruitment of data collectors and data collection process}

Data collectors were recruited based on their previous experience in collecting health survey data. Possession of a first university degree was a prerequisite. The data collectors had a one week intensive training on data collection techniques and pretesting of the tools. The tools were revised based on findings and lessons learnt from the pretesting and then finalised for the study.

\section{Community survey}

Three fieldwork teams (A, B and C), each comprising of a supervisor and four interviewers, were formed to collect 
both qualitative and quantitative data. Team A collected data in the Northern Region and teams B and C worked jointly in the Eastern and Western Regions. Data collection lasted from 01 August 2014 to 23 August 2014.

\section{Selection of communities for household survey}

A selected district had to have a functional CHPS programme already introduced but lacking primary level eye care service. The selection was also based on the availability of an ophthalmic nurse and proximity to a referral hospital or facility. CHPS zones with the highest population were chosen purposively for the study. The number of respondents interviewed per the selected communities in the sub-districts was based on a simple random sampling technique of a probability proportional to size.

The formula for the required sample size was as follows:

$$
\begin{aligned}
m= & D\left[Z_{a} \sqrt{(r+1) P(1-P)}\right. \\
& \left.+Z_{\beta} \sqrt{r p_{1}\left(1-p_{1}\right)+\left(1-p_{2}\right)}\right]^{2} / r\left(p_{2}-p_{1}\right)^{2},
\end{aligned}
$$

where

$m=$ sample size in the intervention group

$r=$ sample size in the control group

$D=$ design effect; 2.0 was used

$Z_{\alpha}=$ the $\mathrm{z}$-score corresponding to the probability with which it is desired to be able to conclude that an observed change of size $\left(p_{2}-p_{1}\right)$ would not have occurred by chance; $Z_{\alpha}=5 \%$ level of significance $=1.96$

$P\left(p_{2}-p_{1}\right) / 2$

[Eqn 2]

$Z_{\beta}=$ the $z$-score corresponding to the degree of confidence with which it is desired to be certain of detecting a change of size $\left(\mathrm{P}_{2}-\mathrm{P}_{1}\right)$, if one actually occurred. Conventionally a power of $80 \%$ is used which is 0.84

$p_{1}=$ the estimated proportion at the time of the first survey;

$p_{2}=$ the proportion at some future date such that the quantity

$\left(p_{2}-p_{1}\right)$ is the size of the magnitude of change it is desired to be able to detect.

$R=$ ratio of control group to intervention group; (2:1). Therefore, $r=2$.

$$
\begin{aligned}
m= & D[1.96 \sqrt{(2+1) 0.55(1-0.55)} \\
& +0.84 \sqrt{2 * 0.5(1-0.5)+0.6(1-0.6)}]^{2} / 2(0.6-0.5)^{2}
\end{aligned}
$$

$m=582$ for intervention group

$\mathrm{rm}=2 \times 582=1164$ for control group

$N=(r+1) m=1746$ for total sample size

As there is no information available on knowledge from other studies in Ghana, the recommended $p_{1}=0.50$ was used and $p_{2}=0.60$ was used to detect a difference of 10 percentage points after the intervention. A total sample size of 1746 respondents (582 in the intervention group and 1164 in the control group) will be required for the survey.

\section{Focus group discussions}

A listing was generated from all sampled CHPS catchment communities, and two communities were randomly selected for FGDs. Two FGDs (one male and one female FGD) were conducted in each of the six sub-districts, giving a total of 12 FGDs. Community members assisted in recruiting FGD participants. Each FGD consisted of 8-10 participants.

\section{In-depth interviews}

A list of all pharmacy or chemical shops and community health volunteers (CHVs) located in the CHPS catchment area of study communities was obtained from the Disease Control Officer in each study district. Where there was more than one eligible respondent, one respondent was interviewed if he or she was willing to participate in the study. In-depth interviews were conducted also with assembly members, chiefs, chemical sellers and CHVs. The assemblyman or assemblywoman were selected based on the communities they represented.

Interviews for the qualitative data were recorded digitally in the local dialects (Akan, Ewe and Gonja) and audio files labelled appropriately for easy retrieval. A word-for-word transcription was made in English by the interviewers. Research assistants were engaged to word process the transcripts. The researchers validated the transcripts by listening to a sample of the tapes to check accuracy of content and translation quality. The transcripts were organised using NVIVO qualitative data analysis software. The transcriptions were coded using identified themes from the interview guide and themes that emerged from the data.

\section{Case narratives}

Case narratives were collected from community members who had had an eye disease in not more than 2 months prior to the data collection or were suffering from an eye disease during the data collection period irrespective of when it started. The patients were recruited through the CHOs, assemblyman or assemblywoman, CHVs or FGDs.

\section{Eligibility}

Women and men aged 18 years and above were eligible to participate in the study. Potential participants who did not give their consent were excluded. Non-residents of the community were also excluded. FGD participants were excluded from the household survey, IDI and the case narrative.

\section{Ethical consideration}

Ethical approval for the study was obtained from the Ethical Review Committee (ERC) of the Ghana Health Service (ethical clearance number: GHS-ERC: 15/03/13). Consent was obtained from participating individuals. Participation was voluntary. Those who consented signed or thumbprinted the consent form to indicate their willingness to participate in the study. 


\section{Results}

\section{Demographic characteristics of study participants}

A total of 1760 people participated in the household survey. There were 924 (52.5\%) females and 836 (47.5\%) males. The age range was $18-101$ years. The majority of the respondents (82\%) were 20-59 years of age. Seventy-two per cent of the participants were married. The main occupation was farming. About $64 \%$ had not registered with the NHIS. More than one-third (34\%) of respondents had been educated only up to the middle or junior high school level. Akan-speaking respondents constituted $42.5 \%$ of the ethnic group (Table 1).

\section{Focus group discussion participants}

Focus group discussions were conducted separately among females and males in the age groups of 25-35 years and 36-55 years. A total of 48 females and 49 males participated in the FGDs (Table 2).

TABLE 1: Demographic characteristics of household survey participants.

\begin{tabular}{|c|c|c|}
\hline Characteristics & $\mathbf{N}$ & Percentage \\
\hline \multicolumn{3}{|l|}{$\operatorname{Sex}(N=1760)$} \\
\hline Male & 836 & 47.5 \\
\hline Female & 924 & 52.5 \\
\hline \multicolumn{3}{|l|}{ Level of education $(N=1760)$} \\
\hline None or no education & 628 & 35.7 \\
\hline Primary school & 267 & 15.2 \\
\hline Middle or JHS & 599 & 34.0 \\
\hline Senior high school & 176 & 10.0 \\
\hline Vocational or technical & 27 & 1.5 \\
\hline Tertiary & 59 & 3.4 \\
\hline Other & 4 & 0.2 \\
\hline \multicolumn{3}{|l|}{ Ethnicity $(N=1760)$} \\
\hline Akan & 748 & 42.5 \\
\hline Ga/Dangme & 39 & 2.2 \\
\hline Ewe & 330 & 18.8 \\
\hline Gonja & 122 & 6.8 \\
\hline Mole/Dagbani & 459 & 26.1 \\
\hline Other & 62 & 3.5 \\
\hline \multicolumn{3}{|l|}{ Main occupation ( $N=1760)$} \\
\hline Farming & 980 & 55.7 \\
\hline Trading & 296 & 15.3 \\
\hline Unemployed & 166 & 9.4 \\
\hline Artisan & 161 & 9.1 \\
\hline Public/Civil servant & 60 & 3.4 \\
\hline Apprentice & 21 & 1.2 \\
\hline Industry & 5 & 0.3 \\
\hline Others & 98 & 5.6 \\
\hline \multicolumn{3}{|l|}{ NHIS card ownership ( $N=1760)$} \\
\hline Card bearing (card available for inspection) & 297 & 16.9 \\
\hline Card bearing (card not available for inspection) & 338 & 19.2 \\
\hline Not registered with NHIS & 1125 & 63.9 \\
\hline \multicolumn{3}{|l|}{ Marital status $(N=1760)$} \\
\hline Married or living together & 1267 & 72.0 \\
\hline Single & 290 & 16.5 \\
\hline Widowed & 104 & 5.9 \\
\hline Divorce or separated & 90 & 5.1 \\
\hline Other & 9 & 0.5 \\
\hline
\end{tabular}

NHIS, National Health Insurance Scheme; JHS, Junior High School.

\section{In-depth interview participants}

In-depth interviews were conducted at the community level with six opinion leaders, four $\mathrm{CHVs}$ and four chemical shop owners (Table 3).

\section{Case narratives}

Eye health narratives were taken from five patients consisting of two women and three men (Table 4).

\section{Knowledge about eye health}

\section{Common diseases in the community}

The survey respondents mentioned malaria and/or fever $(84.8 \%)$, aches and pains $(69.2 \%)$, eye disease $(67.0 \%)$ and

TABLE 2: Background characteristics of focus group discussion participants.

\begin{tabular}{lcc}
\hline Participants & Women & Men \\
\cline { 2 - 3 } & \multicolumn{2}{c}{ Sex } \\
\hline Education & 19 & 14 \\
$\quad$ None & 29 & 35 \\
At least basic education & & \\
Marital status & 0 & 8 \\
$\quad$ Single & 40 & 41 \\
Married & 4 & 0 \\
Cohabiting & 5 & 0 \\
$\quad$ Divorced or separated & & \\
Occupation & 42 & 72 \\
Employed & 6 & 7 \\
$\quad$ Unemployed & & 41 \\
Number of years in community & 14 & \\
$\quad$ Less than 5 years & 24 & \\
$\quad$ More than 5 years & & \\
\hline
\end{tabular}

TABLE 3: Background characteristics of in-depth interview participants.

\begin{tabular}{llllc}
\hline Participant & Age & Sex & Occupation & $\begin{array}{c}\text { Length of stay in } \\
\text { community }\end{array}$ \\
\hline Opinion leaders & 66 & Male & Farmer & 30 \\
& 53 & Female & Secretary & 53 \\
& 70 & Male & Unemployed & 70 \\
& 55 & Female & Farmer & 50 \\
& 50 & Female & Teacher & 50 \\
Community health & 40 & Male & Teacher & 40 \\
volunteers & 42 & Male & Farmer & 14 \\
& 63 & Male & Security man & 40 \\
& 57 & Male & Farmer & 57 \\
Chemical shop & 67 & Male & Farmer & 50 \\
owners & 43 & Male & Chemical shop owner & 15 \\
& 48 & Female & Chemical shop owner & 22 \\
& 42 & Female & Teacher & 42 \\
& 71 & Male & Chemical shop owner & 23 \\
\hline
\end{tabular}

TABLE 4: Background characteristics for case narratives.

\begin{tabular}{lllllll}
\hline Name $\dagger$ & Age & Sex & Occupation & $\begin{array}{l}\text { Educational } \\
\text { status }\end{array}$ & $\begin{array}{l}\text { Marital } \\
\text { status }\end{array}$ & $\begin{array}{l}\text { Length } \\
\text { of eye } \\
\text { problem }\end{array}$ \\
\hline KF & 29 & Male & Kente weaver & None & Married & 2 years \\
KW & 56 & Male & Unemployed & Form 4 & Married & 17 years \\
RT & 30 & Female & Farmer & None & Married & 2 weeks \\
PT & 48 & Male & Farmer & Form 4 & Married & 2 years \\
FL & 39 & Female & Farmer & None & Married & 2 weeks \\
\hline
\end{tabular}

$\dagger$, pseudonyms for participants. 
diarrhoea as common diseases in the community. Eye disease was said to be the third most common health problem.

\section{Healthy and unhealthy eyes}

The ability to see well (85.6\%) and perform everyday duties $(46.6 \%)$ was mentioned as symptoms of healthy eyes. Inability to see or poor vision $(27.9 \%)$ and pain in the eye (11\%) were perceived as symptoms of unhealthy eyes.

\section{Causes of common eye conditions}

The common causes of eye disease mentioned by respondents included kookoo, injury, old age, drinking contaminated water and eating too much gari and cocoyam. A female's FGD group provides evidence of perceived knowledge of common causes of eye disease: 'Some say that the chemicals we use to grow our crops can cause eye sickness'. The fishermen and farmers reported that water and sweat entering the eye during either diving or working on the farm could cause eye disease. Some community members said Apollo could be transmitted from one person to another via contact by either sharing the same sponge and towel or using the same cup with an infected person for washing the face. However, others said that looking into the face of an infected person could cause Apollo. Some others said that eye diseases could be spread by an insect that had already bitten a person who has an eye disease; or when flies settled on the eyes of an infected person and then on food, the consumption of such contaminated food can cause eye infection.

\section{General symptoms of eye diseases}

The general symptoms of eye diseases mentioned by survey respondents included red eyes, itchy eyes, poor vision, tearing or watering and blindness. In a women's FGD, participants recognised a person with eye disease in the following statement: 'The eye ball of the person will be reddish'. An eye disease getting worse could be identified by vision getting poorer, severe pain and increasing redness.

\section{Symptoms of some specific eye diseases}

The survey respondents were asked about their knowledge of some specific eye diseases. Conjunctivitis was recognised as red eye $(87.6 \%)$ with discharge (58.8\%). Only $3 \%$ of respondents mentioned blindness associated with trachoma and 5\% knew that glaucoma causes blindness. The main symptom identified for refractive error was poor vision $(82.5 \%)$. Other symptoms mentioned for refractive error were red eyes, itchy eyes, headache, squinting and blindness. The survey respondents reported that cataract caused poor vision $(60.3 \%)$ and that a white substance may be seen in the eye $(43.8 \%)$. They said a person with poor vision or blindness was often led around (70.2\%) and some community members treated the blind very well but others were either indifferent or hostile to the blind.

\section{Use of spectacles}

Focus group discussion participants said people use spectacles on medical recommendation to see well, to avoid dust and other particles from entering the eye or as sunshades, while others use them for fun. Some participants added that spectacles were sometimes worn to hide eye defects from the public. They concluded that while spectacles could be worn by everyone, some said spectacles were mostly worn either by persons with eye disease or by people aged over 65 years and also by people with 'white-collar' jobs as a sign of class. Some participants said that children should not wear spectacles and that wearing of spectacles would cause deterioration of the sight or may cause the eyes to sink in.

\section{Eye health-seeking behaviour}

\section{Sources of eye health care}

Sources of eye health care available to the communities included CHPS, chemical stores, churches and herbal drug sellers. The chemical sellers were either residents in the communities or itinerant medicine sellers. Apart from the study communities in the Northern Region, study communities in the other zones had one or more chemical sellers who provided care for health problems including eye problems.

Out of the total 1760 respondents interviewed in the household survey, 839 said that either a member of the household or the individual being interviewed had an eye disease within the year prior to the data collection. The most common eye problems mentioned were itchy eyes (62\%) and red eyes (59.1\%). Fifty per cent of the respondents who had suffered an eye problem did nothing, while $21 \%$ went to a health facility (Figure 1). Respondents, who had suffered eye disease (44\%), went to hospital as first point of call and $23 \%$ went to the drug store to buy medication (Figure 2). District hospitals were used by $56.0 \%$ of respondents, while $2 \%$ used regional and tertiary hospitals, respectively (Figure 3). In the health facility, the respondents said that they were either given eye drops or ointment or a prescription to buy medication from a drug or chemical shop. Some of the respondents were given either spectacles or pain reliever or had an eye operation. Some community members sought eye health care from the churches, prayer camp and herbalists because they perceived an underlying spiritual cause.

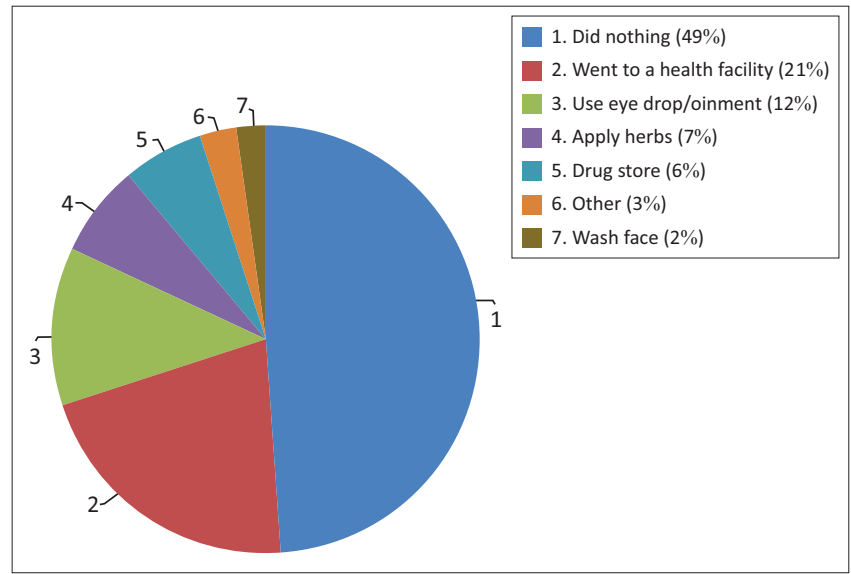

FIGURE 1: Initial action taken in managing eye disease. 


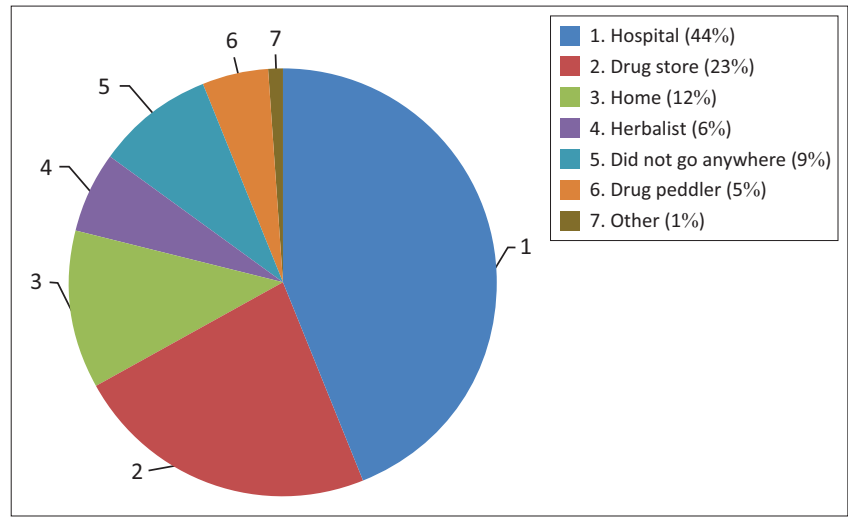

FIGURE 2: First point of call for help for an eye disease.

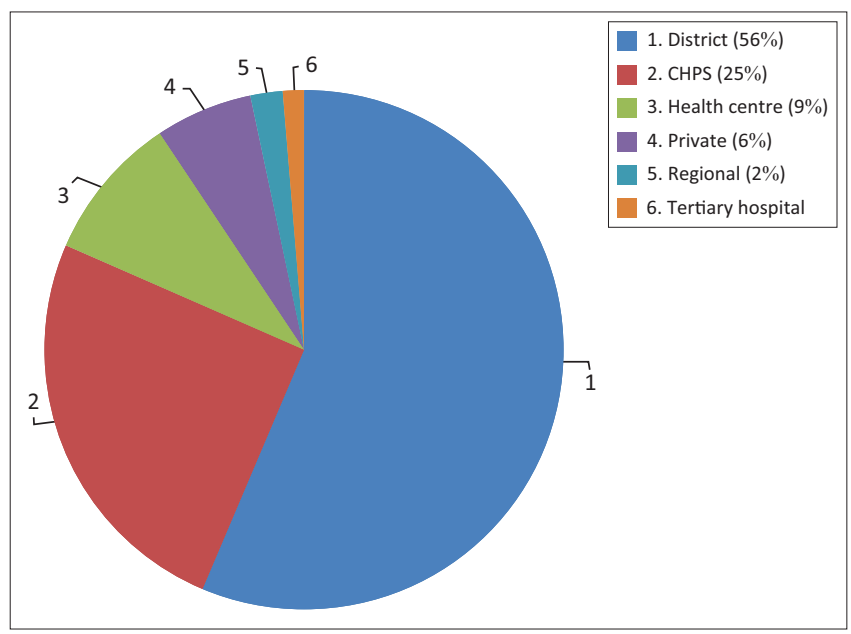

CHPS, Community-based Health Planning and Services.

FIGURE 3: Health facilities visited for treatment of eye disease.

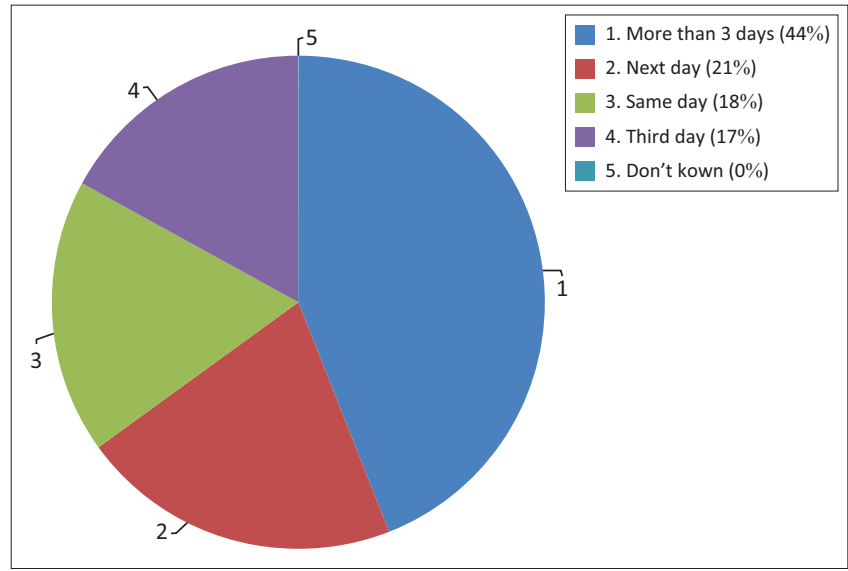

FIGURE 4: Time treatment initiated after onset of disease.

Only $18 \%$ of respondents sought help on the same day they experienced the eye disease; $44 \%$ sought help only after three or more days (Figure 4). The main reason for seeking help was that they had pain $(86 \%)$ in the eye. Respondents who reported using Kohl, antimony powder, on the eyelid margins as cosmetics also believed that it improved eyesight and helped the eyelashes grow. Others used either shea butter or breast milk; self-medicated with leftover eye drops; washed the eye with either seawater or salt water; applied tobacco snuff; drank a mixture of malt and tomato puree or applied herbs. The eclectic approach is captured in the following FGD comments: 'You can go to the hospital and prayer camp at the same time'. And 'We normally say it is kookoo, so when it starts the person goes for kookoo medicine'. Clearly, the local diagnosis influences what course help seeking should take.

\section{Treatment of some specific eye diseases}

Eye drops were mentioned for all types of eye diseases: red eye $(77.3 \%)$, sticky eyelids $(48.6 \%)$, watery eyes and itchy eyes $(64.3 \%)$. Respondents said eye drops were also given for eye injury and trauma, poor vision and even blindness. None of the participants specified the type of eye drops used. Chemical sellers in the communities also used gentamycin and chloramphenicol eye drops or ointment to treat eye disease presented to their shop as this comment illustrates: 'For those who come with itching after giving them the chloramphenicol eye drops the itching stops so they don't go to the hospital'. However, hospital was the first option for poor vision and blindness. Around $43 \%$ of respondents described the treatment they received as very effective. Others said their treatment was ineffective. Some indicated that their eye disease worsened; and yet others said that the disease improved for a while only to re-occur. Even hospital treatment was reported to be ineffective sometimes, as the following comment indicates: 'When we go to the clinic they give us eye drops to put in the eye but it doesn't work or treat

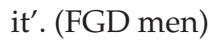

According to the respondents, decisions on type of service used was based on service affordability (56.6\%), availability (52.1\%), accessibility (48.2\%) and quality of service. A number of challenges were associated with seeking eye care. These included lack of eye medications (42.3\%), absence of visiting eye specialists (36.9\%) and eye services being too expensive.

\section{Case narratives}

Five patients were interviewed to understand and appreciate how they sought help for their eye disease. Of the five patients interviewed, three had a history of itching with red eyes and two had injury to an eye - one on her farm and the other during weeding at the workplace. The farmer in this case reported same day to the hospital; the labourer, a day later. The other three patients with itching used selfmedication with local remedies and went to hospital later. According to all five patients, when there was no relief, they sought alternative help. Some patients travelled to other places for better alternatives but those who found no relief eventually resigned to their fate. The challenge with four out of the five patients' histories was late diagnosis. The initial cost for care in the health facility was considered affordable because they utilised the NHIS at the district hospital. However, when they were referred to the next level of care, they failed to take up the referral because of lack of funds for transportation and subsistence outside home. Two of the patients went blind in the affected eye and they said this had a negative impact on their social and economic status. One lost his job as a labourer at the mining company because of 
prolonged absence from work while receiving treatment, and another stopped farming because of persistent itching and tearing of the eyes. All the patients interviewed wished for expert eye care closer to them in their communities.

\section{Discussion}

\section{Knowledge about eye health}

The status of eye disease as the third most common disease in the communities is confirmed by a men's FGD group in the following quote: 'We have a lot of people suffering from malaria here, the eye problems would be number two or three in this community'. The symptoms of eye diseases experienced included red eyes, itching, watering of eyes and swelling of eyelids and blindness. The survey respondents knew the symptoms of healthy and unhealthy eyes. Apart from red eye, which was considered as a symptom of Apollo by all the participants, knowledge about some specific eye diseases like cataract, refractive error, glaucoma and trachoma was poor. Only $3 \%$ and $5 \%$ of respondents associated blindness with trachoma and glaucoma, respectively. An assemblyman in an IDI explained about glaucoma: 'I heard that it is a disease that if not treated you will lose your sight completely and nothing can be done about it'. In reference to again glaucoma, an assemblywoman remarked: 'We thought that the bites of those small black insects we call nkontia found close to large water bodies caused that eye disease'. Such views show the deficient knowledge about some eye diseases.

Isawumi and colleagues ${ }^{15}$ in a study carried out among the adult population in Osun State in Nigeria reported that only $15.8 \%$ of their study population had ever heard of glaucoma. The low awareness of glaucoma has been associated with lower levels of education in Nepal, as reported by Shrestha and colleagues. ${ }^{16}$ The education level of our study population was low, only a third of them having received education up to junior high school level, that is, 9 years of schooling. Probably not surprising our population also had low knowledge of glaucoma.

Focus group discussants and IDI talked about small blackflies near large bodies of water that bite people who live or work in such areas. They believed the bites of these insects caused eye disease: 'Those of us close to large bodies of water where there are small black insects we call nkontia cause eye disease when they bite us'. (IDI Community Health Volunteer)

Nkontia is the local name for Simulium damnosum, which transmits onchocerciasis. Onchocerciasis and trachoma are endemic in Ghana. ${ }^{17}$ Ghana was one of the 11 West African countries where the Onchocerciasis Control Programme (OCP) was launched in 1974. The control programme started with aerial spraying of the blackflies along fast flowing rivers. Community distribution of Ivermectin started in $1984 .^{18}$ Whereas onchocerciasis is transmitted by the bite of the Simulium fly that breeds along fast flowing rivers, trachoma, an eye infection, is transmitted by the eye-seeking fly Musca sorbens that breed in insanitary environments, commonly in human faeces. ${ }^{19}$ The participants knew about flies and eye disease but they did not know the specific eye diseases caused by the two types of flies. A case narrative mentioned the yearly community distribution of Ivermectin for onchocerciasis control.

A Ghana national programme for trachoma control adopted the WHO recommended SAFE strategy. ${ }^{20}$ Trachoma control activities have been implemented since 2000 in the Northern and Upper West Regions of Ghana where trachoma was found to be endemic. ${ }^{21,22}$ Community members reported that face washing and good personal hygiene were enough to prevent eye infection. The 'FE' of SAFE is all about face and hand washing and personal hygiene. FGD women had this to say: 'You can wash the eye with seawater or with your own urine'. Washing your eye with urine can be dangerous, though there is no awareness of this. A patient presented in an eye centre with panophthalmitis of both eyes after using her own urine to wash her red eyes. She went blind in both eyes.

Survey respondents knew cataract is associated with poor vision but only $18.6 \%$ could associate cataract with blindness. Refractive error was known as a cause of poor vision and that spectacles could help one with refractive error to see well. Focus group participants said spectacles are used, among other things, to protect the eyes (Box 1: 8 and 9) People wear spectacles to see well: 'I can't see from afar unless I wear my spectacles' (case narrative). Some Ghanaian men and women

BOX 1: Quotes from qualitative data.

Type of qualitative data - FGD, IDI and patient narrative

1. I I had a personal experience with a small girl with vision impairment in our house. This girl would have fallen into a flaming fire had I not blocked her. Mobility of the blind without any help is very dangerous to their lives'. (FGD women)

2. 'When they don't get anyone to help them they may decide to commit suicide'. (FGD men)

3. II went to the hospital for some drugs but the sickness was still getting worse so I could see the hospital drugs wouldn't help me. One brother came to tell me there is a drug called esro bitters which is bitter, I bought one but the sickness was still the same so I decided to go back to the hospital'. (FGD women)

4. 'We go to them for prayers but it does not help unless one sends the disease to the hospital for treatment and care before it will be treated'. (Case narrative)

5. 'When we have eye disease we go to Bruben or Mechem-fre clinic. If they don' have the drugs they'd refer us to Donkorkrom, which is a big District Hospital'. (FGD men)

6. 'The traditional ones are not expensive; they are mostly free of charge because of the communal nature of the people in the village'. (FGD men)

7. 'The traditional one has no medical alternative if one medicine fails to cure. The hospital has many medical alternatives'. (FGD women)

8. 'They are not punctual at all especially weekends. They complain of lack of medicines. Why would a whole health centre give such excuses, then what is your use?'

9. 'Oh those nurses, they are so full of themselves especially if you are someone who doesn't speak their mother tongue they do not care about us'.

10. 'I spent a lot of money because I had to move from here to Tarkwa. In this village, there is no car moving from here to Breman Asikuma so you could wait from morning till $6 \mathrm{pm}$ before you get a car to Takoradi station; then board a vehicle from Takoradi to Mankessim and from Mankessim to Breman Asikuma. So what I did was when going, I board a vehicle going straight to Accra, alight at Mankessim and then board a vehicle from straight to Accra, alight at Mankessim and then board a vehicle from
Mankesim to Breman Asikuma so I spent lots of money'. (Case narrative)

11. 'If they can treat us here then there is no need travelling all the way to Tarkwa'. (FGD men)

12. 'Yea, let's say it would shorten your journey; if they are able to look at the eyes and give you drugs, it will stop you from going to Salaga and if it's beyond their limit they will refer you to Salaga. It will help the community and other communities nearby'. (Community Health Volunteer)

13. 'The government did the health insurance to cover our bills but when you get there they would be telling you 'this and that' are not covered with the health insurance and redirect you to the drug store'. FGD women

FDG, focus group discussion; IDI, in-depth interviews. 
see spectacles as adornment and a status symbol. This has been remarked by FGD women participants in this study as follows: 'Some people wear it just for fun'. Some participants said children did not qualify to wear spectacles, probably implying that either children did not suffer from eye disease or that early use of spectacles would result in future eye problems, such as sight deterioration or sunken eyes. For some parents, lack of funds to buy spectacles may well be the problem as reported by Faal and colleagues ${ }^{23}$ and Odedra and colleagues. ${ }^{24}$

Participants in this study were aware of the effects of poor vision or blindness. The blind were often a liability to the family and community. Children used to lead the blind missed school. The blind were often unable to socialise and some even became depressed (Box 1: quotes 1 and 2). These comments seem to echo what Javitt and colleagues ${ }^{25}$ reported, namely, that cataract-blind patients said loss of sight brought feelings of disempowerment, anger and frustration. The blind participants in this study were said to be treated with indifference and some people were even hostile to them. Ezegwui and colleagues ${ }^{26}$ reported that blind children were stigmatised. People with disability were often discriminated against and they faced barriers in employment. They did not have access to services that could assist them to overcome barriers they face in society and so become depressed in life. The condition of the blind, as captured, needs to be reconsidered in the light of the United Nations 'Convention on the Rights of Persons with disability' passed in 2008. ${ }^{27}$ This is an opportunity to protect and promote the rights of people with disability to develop in a more inclusive society. Though the convention was ratified in Ghana in 2012, its implementation is still at the stage of advocacy and awareness creation. A Disability Act based on welfare approach had been in place since 2006 but this is now being amended based on the Rights Approach (Obeng P 2016, personal communication, May 23).

\section{Health-seeking behaviours}

Sources for health-seeking available to community members were CHPS and the referral hospitals at district, regional and tertiary hospitals and chemical and drug stores. However, community members also visit herbalists, churches and prayer camps. In seeking help for a health problem, people alternate between different practitioners rather than seek one avenue or provider as reported by Ngugi and colleagues ${ }^{28}$ in their study on transmission of sexually transmitted diseases in Kenya. The FGD and case narrative comments (Box 1: quotes 3 and 4) testify to a tendency to exploit different eye care systems sequentially or simultaneously.

Very few, (18.0\%) of survey respondents, would seek immediate help when they had an eye disease. A patient who had an eye injury on her farm reported: 'I did not apply anything at the farm on the eye; I just took it straight away to the hospital' (case narrative). FGD men's group reported that they sought help at the community clinic but were referred to the district hospital when drugs were not available at the local facility (Box 1: quote 5). Most would wait several days, if not weeks or months, after the onset of the disease, and would only seek help either because they were in pain, the eye was 'red', or they feared they were losing their sight. In such cases, they ended up in hospital when complications had already occurred. Hospital treatment, then, becomes only palliative. This situation has been reported by Al-Attas and colleagues ${ }^{29}$ that poverty, among other factors, was a major contributor to the delay in accessing eye care. There were also those respondents who did nothing, either because they could not afford the cost of treatment or because they did not know where to go. Senyonjo and colleagues ${ }^{4}$ reported in a study in Kwara State, Nigeria, that the most common reason for people not seeking treatment was a belief that the problem was not important or they did not know where to go. In this study, respondents used 'no money' as the reason for not seeking help at a health facility.

Those who preferred to go to the traditional healer claimed that the healers were polite and friendly, more sympathetic and often respected their privacy. Their treatment was considered inexpensive and within the means of the less privileged who depended on social capital as the following statement illustrates (Box 1: quote 6). However, the use of traditional medicines has been reported to damage the eye and lead to blindness. Foster and Sommer ${ }^{30}$ have reported that traditional preparations are a cause of bilateral corneal ulceration leading to blindness in children in Africa.

Most focus group participants preferred hospital treatment where skilled personnel and opportunity for referral for expert care were available. FGD women were of such persuasion (Box 1: quote 7). The implication is that people associated availability of eye service and quality of care with hospital. While the above view is typical, nevertheless, some participants were not happy using the health facility because they said that some health workers were not punctual and kept patients waiting (Box 1: quote 8) Staff attitude was reported to be poor; sometimes medicines were not available, and there were language barriers for some participants. (Box 1: quote 9). The predominant language in some study communities is Akan, which is understood by about $70 \%$ of Ghanaians. However, those who neither speak English nor Akan had communication problems.

The cost of hospital treatment and the distance community members had to travel for care is a real challenge. A case narrative reports on the costs and time spent to take up a referral. He had to travel several kilometres from his village through Tarkwa, all in the Western Region to Breman Asikuma in the Central Region (Box 1: quote 10). The community members reported that if the service is made available in the community and the $\mathrm{CHO}$ are trained and given equipment and medicines community members would not need to travel far for eye care (Box 1: quotes 11 and 12).

The participants said service at the hospital was expensive and hospital eye health service was unaffordable. To reduce 
out of pocket expenditure for health care, the National Health Insurance Scheme (NHIS) has been established and its minimum package covers out-patient care including eye health and cataract surgery. ${ }^{31}$ However, only $34 \%$ of the survey respondents were registered with the NHIS. The NHIS medicines list does not cover specialised services, like eye care and even registered patients usually buy the medicines for specialised services. This is often difficult for patients to understand as demonstrated in (Box 1: quote 13). Boadi-Kusi and colleagues ${ }^{32}$ reported in a study among cocoa farmers in Ghana that even though $82.7 \%$ of the cocoa farmers were registered with NHIS, only $25.9 \%$ used hospital services. Others used either herbal preparations $(18.9 \%)$ or selfmedication (16.8\%). This finding corroborates the finding of our study that people in areas where eye health is not readily accessible tend to seek help that is closer to them.

\section{Conclusion}

This study has identified eye disease as a common health problem in all the study communities. The study participants could recognise a healthy eye and differentiate it from an unhealthy eye. However, there was a wide knowledge gap regarding the causes and prevention of eye diseases. They preferred to seek help closer to their communities. Some community members' comments on previous experiences with eye disease show that some tended to exploit different eye care systems sequentially or simultaneously by using the services of different practitioners. Thus, a community member would go to a prayer camp, a traditional healer and a health facility. Others used herbal preparations or bought over-the-counter medication, hoping to attend hospital later when they have saved enough money. Some would take no action until the eye disease had gotten worse or if they were afraid of losing their eyesight. There is evidence that community members have not taken advantage of the NHIS.

The case narratives on recent eye disease episodes confirm that eye health services were not readily available in their communities and they were referred to higher levels of care. They found the direct and indirect costs too expensive and so did not take up their referrals. The only one who took up the referral had to travel several kilometres and spent a substantial amount on hospital fees and incidental expenses.

Every individual has the right to sight and the right to quality eye health. Community members desire quality eye health services closer to them. With the extent of poverty among the hard-to-reach communities, making the service available and accessible is not enough, if it is not affordable.

\section{Recommendations}

- Eye health service needs to be made affordable. People need to be educated and encouraged to register with the NHIS.

- The attitude of the community health providers must be acceptable. They need to be trained and equipped to empower them to provide primary level eye care and refer all other eye diseases.

- The referral system must be strengthened for quality eye health delivery.

- Community rehabilitation is needed for the blind at the community level.

- The capacity of community chemical and medicine shop owners needs to be built with eye health knowledge so that they could know their limits at the community.

- Traditional medicine practitioners and herbalists in the community should be involved in eye health so that they will appreciate the effects of traditional preparations on the eye.

When eye health is available, readily accessible, affordable and acceptable to community members, community members can be expected to change their eye health-seeking behaviours.

\section{Acknowledgements}

The study has been financially funded by Orbis International and the authors are most grateful. The authors would also like to thank all the field staff and data managers who worked tirelessly towards the collection of data, data entry and management. They are indebted to all community members who consented to participate in the study, the Ghana Health Service-Research and Development Division (GHS-RDD), PPME (Policy Planning Monitoring and Evaluation Division) and Eye Health Unit, Institute of African Studies, University of Ghana and Ghana Eye Foundation (GEF) for providing permission to undertake this study.

\section{Competing interests}

The authors declare that they have no financial or personal relationships which may have inappropriately influenced them in writing this article.

\section{Authors' contributions}

I.O., L.B. and M.H. conceived and designed the study. A.K.A., A.O., I.O., M.H. and L.B. reviewed the proposal. L.B. and I.O. conducted the study. I.O., M.H., L.B., A.K.A. and A.O. analysed the data. The manuscript was written and reviewed by A.O., M.H., I.O., L.B. and A.K.A.

\section{Funding information}

Funding for this study was provided by the Orbis International.

\section{References}

1. Lindfield R. The prevalence of Non-Vision Impairing Ocular Conditions (NVIC): A literature review. Unpublished; 2009.

2. Hussain $A$, Awan $H$, Khan MD. Prevalence of non-vision impairing ailments in a village in Chakwal district, Punjab, Pakistan. Ophthal Epidemiol. 2004;11(5);407-
420. https://doi.org/10.1080/09286580490888799

3. Kimani K, Lindfield R, Senyonjo L, Mwanki A, Schmidt E. Prevalence and causes of ocular morbidity in Mbeere District, Kenya. Results of a Population-Based Survey. PLoS One. 2013;8(8):e70009. https://doi.org/1371/journal.pone.0070009 
4. Senyonjo L, Lindfield R, Mahmoud A, Kimani K, Sanda, Schmidt S. Ocular morbidity and health seeking behaviour in Kwara State, Nigeria: Implications for delivery of eye care services; 2014. Open Access.

5. WAHO. Resolution for the transformation of blindness prevention and control programs into Eye Care Programs. 11th Ordinary Session of the Assembly of Health Ministers of ECOWAS; 2010 Apr 22-24; Freetown, Sierra Leone.

6. Hagan M. Review: Eye Clinic data. Ghana Health Service; 2012. Unpublished.

7. Unite for Sight: A successful summer of eye care in Ghana [homepage on the Internet]. [cited 2011 May 20] http://www.uniteforsight.org/archive/newsletter/ vol1_num9.html\#9: 2006

8. Etya'ale D. VISION 2020 Update - Addressing the challenges of needless blindness in the world. Primary Eye Care Workshop for West Africa; 2008 Mar 18-20; Banjul.

9. Addy J, Dawson M, Fiadoyor S, Boye O. Report on rapid assessment of avoidable blindness in Eastern Region of Ghana; 2009 (Unpublished report).

10. Wiafe B, et al. Ghana blindness and visual impairment study 2015 report [homepage on the Internet]. 2015 [cited August 2018]. Available from: https:// www.iapb.org/vision-2020/ghana-national-blindness-and-visual-impairmentstudy/

11. Ghana Health Service: Community Health Planning and Services (CHPS) Operational Policy. Ghana Health Service Policy Document No. 20. Accra: Ghana Health Service; 2005

12. Ghana Health Service: Community-based Health Planning and Services - Revised Implementation Guidelines. Final draft post-validation report, Accra, Ghana Health Service; February 2015.

13. Du Toit R. An overview of Primary Eye Care in Sub-saharan Africa - A retrospective survey 2006-2012. Compiled for International Agency for the Prevention of Blindness. 2014 [cited 2015 Jan]. Available from https://www.iapb.org. 2014

14 National Eye Health Programme: Imagine Ghana free of avoidable blindness Framework for action.2004-2008. National Eye Care Unit. Printed 2004 .Ghana Health Service, Accra, Ghana.

15. Isawumi MA, Hassan MB, Akinwusi PO, et al. Awareness of and attitude towards glaucoma among an adult rural population of Osun State, Southwest Nigeria. Middle East Afr J Ophthalmol. 2014 Apr-Jun;21(2):165-169. https://doi. org/10.4103/0974-9233.129769

16. Shrestha MK, Guo CW, Maharjan N, Gurung R, Ruit S. Health literacy of common ocular diseases in Nepal [homepage on the Internet]. [cited 2015 Sep 02]. http:// www.biomedcentral.com/1471-2415/14/2

17. Sarkies JWR. Onchocerciasis and trachoma in the Gold Coast. Ann Trop Med Parasitol. 1952;46(3):214-217. https://doi.org/10.1080/00034983.1952. 11685524
18. World Health Organisation. Prevention of blindness and visual impairment Onchocerciasis control programme. http://www.who.int/blindness/partnerships/ onchocerciasis_OCP/en/

19. Emerson PW, Bailey RL, Madhi SO, Walraven GE, Lindsay SW. Transmission ecology of the fly Musca sorbens, a putative vector of trachoma. Trans R Soc Trop Med Hyg. 2000;94:28-32. https://doi.org/10.1016/S0035-9203(00)90427-9

20. WHO. Report of the 2nd global scientific on trachoma. Geneva: WHO; 2003.

21. Yayemain D, Hagan M, Ahorsu F, Aboe A, Seidu A, Gyapong J. Report on baseline trachoma prevalence study in Northern and Upper West Regions. Ghana: Ministry of Health; 2003

22. Hagan M, Yayemain D, Ahorsu F, Aboe A. Prevalence of active trachoma two years after control activities. Ghana Med J. 2009;43(2):54-60.

23. Faal H, Matafeni T, Du Toit R, Manneh K, Khan NU, Awan H. Development, vision and eye health: Perceptions of communities in Senegal and in The Gambia. Sightsavers; 2008.

24. Odedra N, Wedner SH, Shigongo ZS, Nyanali K, Gilbert C. Barriers to spectacle use in Tanzania Secondary School students. Ophthal Epidemiol. 2008;15(6):410-417. https://doi.org/10.1080/09286580802399094

25. Javitt J, Sommer A, Venkataswamy G. The economic and social impact of restoring sight. In: Henkind P, editor. ACTA: 24th International Congress of Ophthalmology. Philadelphia, PA: J B Lipincott, 1983; pp. 1308-1311.

26. Ezegwui IR, Umeh RE, Ezepue UF. Causes of childhood blindness: Results from schools for the blind in south eastern Nigeria. Br J Ophthalmol. 2003;87:20-23. https://doi.org/10.1136/bjo.87.1.20

27. United Nations convention on rights of persons with disability. 2008 [cited 2012 August 28]. Available from: http://www.un.org/esa/socdev/enable/convtext.htm

28. Ngugi MS, Bradley EN, Njeru JE, et al. Health care seeking behaviour related to the transmission of sexually transmitted diseases in Kenya. Am J Public Health. 1994;84:1947-1951.

29. Al-Attas AH, Williams CD, Pitchforth EL, O'Callaghan CO, Lewallen S. Understanding delay in accessing specialist emergency eye care in a developing Country: Eye
trauma in Tanzania. Ophthal Epidemiol. 2010;17(2):103-112. https://doi. org/10.3109/09286580903453522

30. Foster A, Sommer A. Childhood blindness from corneal ulceration in Africa; cause, prevention and treatment. Bull World Health Organ. 1996;64(5):619-623.

31. National Health Insurance Scheme: Tariff Operation Manual, Service Package. Eye care Services page 8; 2013. exclusion services pp. 8-9.

32. Boadi-Kusi Samuel Bert, Rekha H, Percy MK. Ocular injuries and eye care seeking patterns following injuries among cocoa farmers in Ghana. Afr Health Sci. 2016;16(1):255-265. https://doi.org/10.4314/ahs.v16i1.34 